\title{
Fotojornalismo e os afetos como valores-notícia
}

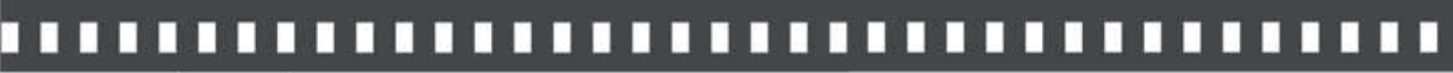

\author{
Wagner Souza e Silva
}

Artigo recebido em: 05/03/2018

Artigo aprovado em: 26/06/2018 


\section{Fotojornalismo e os afetos como valores-notícia}

Photojournalism and the affections as news values

Wagner Souza e Silva*

Resumo: Expandindo-se o conceito de valor-notícia, este artigo tem o objetivo de propor mecanismos teóricos para se observar o componente emocional presente na produção da informação. Propõe-se o fotojornalismo como a expressão dos afetos como valores-notícia, tendo em vista não só o apelo emocional que é intrínseco às imagens, mas também a sua circulação potencializada pelas dinâmicas das redes sociais, o que parece reconfigurar a ideia de sensacionalismo na prática jornalística.

Palavras-chave: Fotojornalismo. Valor-notícia. Redes sociais. Sensacionalismo.

Abstract: Expanding the concept of value-news, this article aims to propose theoretical mechanisms to observe the emotional component present in the production of news information. Photojournalism is proposed as the expression of affections as news-values, given not only the emotional appeal that is intrinsic to images, but also its circulation enhanced by the dynamics of social networks, which seems to reconfigure the idea of sensationalism in the practice of journalism.

Keywords: Photojournalism. News value. Social media. Sensationalism.

* Doutor. Professor da Escola de Comunicação e Artes, Universidade de São Paulo. 


\section{Introdução}

Notando-se que o acesso ao jornalismo tem sido cada vez mais mediado pelas redes sociais, há de se indagar sobre de que maneira esta mediação influencia a dinâmica dos próprios veículos e a forma como estes constroem suas narrativas informativas, visto que tais redes estão permeadas por narrativas confessionais, onde seus usuários, cada vez mais íntimos das interfaces e práticas estabelecidas, participam de um ambiente de forte apelo dialógico, que é modulado tanto pelas informações objetivas que ali circulam, como também pelas relações sociais e emoções que estruturam esse cenário.

As reações e respostas às notícias tendem a ser imediatas, traduzidas em likes, compartilhamentos ou comentários, quase sempre espontâneos e fortemente carregados de opiniões que expressam posições e gostos mais íntimos, fazendo com que a experiência de informar-se seja decisivamente pautada por uma relação afetiva com estes ambientes.

Assim, buscando explorar o conceito de valor-notícia (news value), este artigo tem o objetivo de expandir sua aplicação para além dos critérios objetivos concernentes à informação noticiosa, a fim de se reconhecer o campo afetivo como um valor e critério de noticiabilidade, com a intenção de levantar hipóteses para uma investigação teórica capaz de fazer emergir o componente emocional presente na rotina de produção do jornalismo, seja nos processos de seleção, seja na construção das narrativas informativas.

Para circunscrever este ensaio, propõe-se uma atenção especial ao universo imagético deste cenário, visto todo o apelo emocional que a imagem naturalmente parece portar, sobretudo 
quando comparada ao texto como veículo de informação jornalística. Como bem observa Mata (2012, p. 5),

[...] o jornalismo tem inscrito na sua natureza uma vocação espectral: ele é, por definição, o relato das coisas acontecidas e já mortas. Mas, quando o dispositivo narrativo jornalismo se fixa cada vez mais em imagens, precisamos de pensar que ordem da experiência coletiva é esta que funda a maioria de nossas percepções e juízos sobre o mundo.

O ambiente digital, com suas múltiplas telas, favorece enormemente o uso de imagens e, no caso do jornalismo, não há como contornar a evidenciação de um protagonismo atual das imagens jornalísticas. E mesmo reconhecendo todo o peso que a imagem televisiva ou o vídeo possui neste cenário, propõe-se, por fim, um recorte dentro deste universo imagético jornalístico, priorizando-se aqui o fotojornalismo como linha de frente para as reflexões a serem expostas.

Consagrado por sua tradição consolidada ao longo do século XX, o fotojornalismo, enquanto recorte, se justifica também pelo fato de que parece haver um incremento no espaço para a sua circulação, tendo em vista, sobretudo, a centralidade midiática dos smartphones com suas telas portáteis, câmeras fotográficas e redes sociais baseadas no compartilhamento de fotografias.

Seja por intermédio das fotografias curadas por empresas comunicacionais, seja por meio dos fotojornalistas ou fotógrafos cidadãos, a informação jornalística passa a estar constantemente envolta pela imagem imersa na ambiência das redes sociais, tornando a realidade dos afetos um vetor de determinação dos 
valores-notícia, e assim passam também a pautar a relevância do que é colocado em circulação.

\section{Preâmbulo Filosófico: Espinosa e a Realidade dos Afetos}

A partir do momento em que a forte carga subjetiva do público passa a ser um componente mais efetivamente atuante na circulação da informação, a sua dimensão afetiva passa a ser um elemento fundamental a se observar. O próprio conceito de pós-verdade', em voga nos círculos intelectuais de estudos da comunicação, é, de certa forma, a expressão ou consequência de tal dimensão: opta-se por crer na informação a partir de sua adequação aos princípios, valores e emoções de seu espectador, ignorando a porção objetiva dos fatos narrados. Tal conceito denota, pretende-se aqui demonstrar, a realidade concreta dos afetos na vida cotidiana.

Num artigo deste autor, em que o objetivo foi a abordagem das narrativas fotográficas que se dão nas redes (SOUZA E SILVA, 2014), foi apontada a frente teórica da Virada Afetiva (Affective Turn), sistematizada pela pesquisadora norte-americana Patricia Clough (2007), como um caminho a trilhar para "abarcar este contexto de subjetividade exacerbada" nesses ambientes. Tal frente teórica, nas ciências sociais,

1 "Segundo o dicionário britânico, uma das principais referências para a catalogação de novas palavras e expressões, o termo pós-verdade teve seu uso inflacionado em $2000 \%$ neste último ano, embora circule com certa regularidade há pelo menos uma década [...] Utilizada pela primeira vez pelo dramaturgo sérvio-americano Steve Tesich em 1992, a expressão diz respeito a circunstâncias nas quais fatos objetivos têm menos importância do que crenças pessoais, onde a verdade vale menos que a opinião" (BORGES, 2017). 
[...] tem explorado a complexa relação entre poder, subjetividade e emoção, os lugares da emoção, afeto, sentimentos e sentimentalismo dentro da teorização, a dimensão afetiva das normas, o afeto como uma condição e possibilidade de subjetividade, e o investimento emocional e afetivo nas normas sociais como um modo constitutivo da subjetivação (ATHANASIOU; HANTZAROULA; YANNAKOPOULOS, 2008, p. 2).

No entanto, conforme apontado no mesmo artigo, o interesse maior consistia no fato de que tal frente teórica se sustenta na filosofia dos afetos de Espinosa (século XVII), um filósofo "profundamente relevante para qualquer discussão sobre a emoção e sentimentos humanos." (DAMÁSIO, 2003, p. 22).

Espinosa, para pensar a questão da convivência humana e assim forjar seu tratado sobre ética, cuja primeira publicação se deu em 1677, propôs um sistema filosófico baseado na experiência sensível, onde corpo e mente ocupariam o mesmo nível, não havendo assim, tal como no sistema filosófico de seu contemporâneo, Descartes, uma hierarquização da mente (razão) sobre o corpo.

Os sentimentos e as emoções, que, a princípio, poderiam ser definidos como os afetos, seriam pensamentos fundamentais para determinar a ação humana, mas que não deveriam ser equiparados ao pensamento objetivo das ideias: trata-se de uma "ideia confusa", uma "paixão do ânimo" (ESPINOSA, 2009, p. 152). Para Espinosa, alegria e tristeza seriam os afetos primários e, por isso, as balizas de todos os outros afetos. Por exemplo,

[...] a esperança é "uma alegria instável, surgida da ideia de uma coisa futura ou passada, de cuja realização temos alguma dúvida"; o medo é "uma 
tristeza instável, surgida da ideia de uma coisa futura ou passada, cuja realização temos alguma dúvida"; a segurança é "uma alegria surgida da ideia de uma coisa futura ou passada, da qual foi afastada toda causa de dúvida"; ou ainda "o desespero é uma tristeza surgida da ideia de uma coisa futura ou passada, da qual foi afastada toda causa de dúvida" (ESPINOSA, 2009, p. 152).

A partir de Espinosa, os sentimentos de esperança, medo, segurança, desespero, dentre inúmeros outros, entendidos sob a égide dos afetos, são o que há de mais real na experiência humana: a circunscrição deste tipo de pensamento em torno da própria noção de ideia torna os afetos um tipo de pensamento que seria o mais originário na mente humana, ao mesmo tempo em que está intimamente conectado com o corpo e o mundo exterior. Damásio observa tal "ubiquidade dos sentimentos":

[...] os sentimentos de dor e prazer são os alicerces da mente. É possível não dar conta desta simples realidade porque as imagens dos objetos e dos acontecimentos que nos rodeiam, bem como as imagens das palavras e frases que os descrevem, ocupam toda a nossa modesta atenção, ou quase toda. Mas é assim. Os sentimentos de prazer, ou de dor, ou de toda e qualquer qualidade entre dor e prazer [...] são a mais universal das melodias, uma canção que só descansa quando chega o sono, e que se torna num verdadeiro hino quando a alegria nos ocupa, ou se desfaz num lúgubre réquiem quando a tristeza nos invade (DAMÁSIO, 2003, p. 17).

As sensações e as emoções desencadeadas por meio de uma experiência sensível são aquilo que rege o comportamento humano, e definem a vontade e o desejo do homem para a ação, em 
busca da satisfação própria, que, por sua vez, se dá pela experiência afetiva. Seria possível, portanto, não só considerar os afetos como "alicerces da mente", tal como explicitado por Damásio, mas, principalmente, como motores da ação humana, baseados numa lógica de balizamento a partir dos afetos primários: a alegria, responsável pelos afetos propulsionadores; a tristeza, responsável pelos afetos refreadores.

É, de certa forma, o que justifica a grande aceitação do universo das redes como uma experiência de vivência, pois as relações que ali se estabelecem são concretas nesse sentido que aqui se busca desenvolver. Não à toa, e para além da experiência real dos sentimentos, também é importante notar o caráter mobilizador destas redes (Primavera Árabe, no Egito, e o Movimento Passe Livre, no Brasil, como exemplos dos mais notórios), o que, podese supor, deriva deste potencial mobilizador dos afetos. A respeito dessa relação entre a emoção (afetos) e a mobilização, DidiHuberman reforça:

[...] uma emoção não seria uma e-moção, quer dizer, uma moção, um movimento que consiste em nos pôr para fora (e-, ex) de nós mesmos? Mas se a emoção é um movimento, ela é portanto, uma ação: algo como um gesto ao mesmo tempo exterior e interior, pois, quando a emoção nos atravessa, nossa alma se move, treme, se agita, e o nosso corpo faz uma série de coisas que nem sequer imaginamos (DIDIHUBERMAN, 2016, p. 25-26).

A presença do jornalismo e conteúdo informativo nas redes sociais presume, portanto, não só um campo de embates entre a razão (o campo das ideias objetivas) e os afetos (as emoções e 
sentimentos, as "ideias confusas"), mas um campo de embates entre realidades: em outras palavras, a abstração da representação da realidade que o jornalismo inevitavelmente traz confrontada com a real concretude dos afetos de seus consumidores de notícias e informação.

\section{A Percepção dos Afetos no Jornalismo a Partir do Conceito de Valor-Notícia}

O estudo em torno do conceito de valor-notícia promovido por Silva (2014), que sistematiza e organiza a abordagem do termo por diversos autores, reconhece a sua complexidade, mas converge suas diversas vertentes para uma direção em que o termo seja entendido, prioritariamente, como um "atributo do acontecimento".

O que faz um determinado acontecimento tornar-se notícia é a portabilidade de determinadas características que o qualificam como tal. "Ser um fato atual ou um acontecimento portador de algum dado novo é o princípio primeiro do jornalismo" (SILVA, 2014, p. 63), mas, segundo a autora, também outros valores são decisivamente influenciadores no processo de seleção de notícias, tais como proximidade, proeminência, raridade, conflito, impacto, surpresa, governo, polêmica, entretenimento/curiosidade, conhecimento/cultura e tragédia/drama, dentre diversos outros. A tabela a seguir demonstra a complexidade e amplitude de sua abordagem a respeito das possíveis variáveis de termos que podem ser encarados como valores-noticia, tendo como âncora a diversificação de abordagens de vários autores² (figura 1).

2 Os autores elencados na tabela não foram referenciados neste texto, mas 
Figura 1 - Tabela com a sistematização de valores-notícia referidos por seus respectivos teóricos do jornalismo.

\section{Elencos de valores-notícias}

Stieler: novidade, proximidade geográfica, proeminência e negativismo.

Lippman: clareza, surpresa, proximidade geográfica, impacto e conflito pessoal.

Bond: referente à pessoa de destaque ou personagem público (proeminência); incomum (raridade); referente ao governo (interesse nacional); que afeta o bolso (interesse pessoal/econômico); injustiça que provoca indignação (injustiça); grandes perdas de vida ou bens (catástrofe); conseqüências universais (interesse universal); que provoca emoção (drama); de interesse de grande número de pessoas (número de pessoas afetadas); grandes somas (grande quantia de dinheiro); descoberta de qualquer setor (descobertas/invenções) e assassinato (crime/violência).

Galtung e Ruge: freqüência, amplitude, clareza ou falta de ambigüidade, relevância, conformidade, imprevisão, continuidade, referência a pessoas e nações de elite, composição, personificação e negativismo.

Golding-Elliot: drama, visual atrativo, entretenimento, importância, proximidade, brevidade, negativismo, atualidade, elites, famosos.

Gans: importância, interesse, novidade, qualidade, equilíbrio.

Warren: atualidade, proximidade, proeminência, curiosidade, conflito, suspense, emoção e conseqüências.

Hetherington: importância, drama, surpresa, famosos, escândalo sexual/crime, número de pessoas envolvidas, proximidade, visual bonito/atrativo.

Shoemaker et all: oportunidade, proximidade, importância/impacto, conseqüência, interesse, conflito /polêmica, controvérsia, sensacionalismo, proeminência, novidade/curiosidade/raro.

Wolf: importância do indivíduo (nível hierárquico), influência sobre o interesse nacional, número de pessoas envolvidas, relevância quanto à evolução futura.

Erbolato: proximidade, marco geográfico, impacto, proeminência, aventura/conflito, conseqüências, humor, raridade, progresso, sexo e idade, interesse pessoal, interesse humano, importância, rivalidade, utilidade, política editorial, oportunidade, dinheiro, expectativa/suspense, origi-nalidade, culto de heróis, descobertas/ invenções, repercussão, confi-dências.

$$
\text { Fonte: Silva (2014 p. 102). }
$$

Segundo Silva (2014, p.106), “definir valores-notícia como atributos do acontecimento e reconhecê-los ao mesmo tempo como construção social e cultural é apenas um primeiro procedimento

estão devidamente elencados nas referências do texto original que apresenta esta tabela (SILVA, 2014). 
para pensar a noticiabilidade, cujo processo exige muitas outras reflexões".

[...] ora, ao tratar jornalisticamente os fatos na produção material da notícia, a seleção e hierarquização recorrem sim aos valores-notícia. Mas estes agem aqui apenas como uma parte do processo, pois nessas escolhas sequenciadas entrarão outros critérios de noticiabilidade, como formato do produto, qualidade da imagem, linha editorial, custo, público alvo, etc. (SILVA, 2014 p. 56).

Para a autora, há uma distinção entre valores-notícia que seriam as características do fato em si - e outros conjuntos de critérios de noticiabilidade - relacionados ao tratamento do fato (idem). Assim, os valores-notícia são mais do que uma listagem de atributos da notícia, pois "requerem um conhecimento consensual sobre o mundo", operando com uma "estrutura de retaguarda social, profunda e escondida" (PONTE apud SILVA, 2014, p. 100).

É exatamente neste sentido que se busca aqui reconhecer os afetos como valores-notícia fundamentais para a definição de outros critérios de noticiabilidade: em outras palavras, isto é, nos termos da autora, os afetos poderiam ser entendidos como parâmetros que tanto expressam um "conhecimento consensual sobre o mundo" como também denotam as "profundas estruturas de retaguarda social". E essa "profundidade" e esse "consenso", se entendidos a partir de Espinosa, revelariam que esta possibilidade de se delinear os afetos como valores-notícia significaria, de certa modo, uma maneira mais consciente e imediata de lidar com a dimensão ética da informação.

Nota-se que, a partir da tabela reproduzida (figura 1), 
os valores-notícia que mais parecem se aproximar da dimensão afetiva da notícia apontam para os termos emoção e drama (ou dramaticidade). Targino (2009), ao também analisar tais dinâmicas de percepção e valorização de aspectos para a noticiabilidade, destaca o critério "dramatização":

[...] a dramatização é um dos valores-notícia mais usados nas redações jornalísticas. Mantém duas faces, cujas fronteiras são tênues e quase imperceptíveis: uma é a arte de o jornalista tornar a notícia mais atraente e, quiçá, mais comovente; a segunda é fazer drama, acercando-se do sensacionalismo. Por isso, há certa tendência de racionalizar o acontecimento em excesso, relatando-o com frieza ou de rejeitar, de imediato, algumas temáticas (TARGINO, 2009, p.159).

Targino cita outro importante critério, que também pode ser extraído da tabela da figura 1: o sensacionalismo. De certa forma, quando se fala em sensacionalismo no jornalismo, isto é, no manejo e priorização de sensações em detrimento da objetividade informativa, refere-se ao potencial afetivo de uma determinada notícia. Nesse sentido, ao se explorar os afetos como valoresnotícia, tem-se a possibilidade de uma decomposição deste termo, isto é, um aprofundamento no entendimento do sensacionalismo a partir de unidades mais específicas.

A figura 2 intenta explorar essa decomposição a partir de alguns dos afetos elencados por Espinosa, lembrando que todos eles derivam, ou da alegria (afetos que aumentam as potências do pensar e do agir), ou da tristeza (afetos que diminuem e refreiam o pensamento e a ação): 
Figura 2 - Afetos abordados por Espinosa em seu sistema filosófico

\begin{tabular}{|c|c|}
\hline "Afetos Positivos" & "Afetos Negativos" \\
\hline Alegria & Tristeza \\
\hline Admiração & Desprezo \\
\hline Amor & Ódio \\
\hline Atração & Aversão \\
\hline Adoração & Escárnio \\
\hline Esperança & Medo \\
\hline Segurança & Desespero \\
\hline Gáudio & Decepção \\
\hline
\end{tabular}

Fonte: Espinosa (2009).

Explorando tais afetos destacados ${ }^{3}$, enquadrando-os como valores-notícia, seria possível até expandir a questão para além do sensacionalismo, este que normalmente opera com uma agenda pautada por "afetos negativos", como medo, desespero, ódio e aversão, típicos das noticias policialescas e de tragédia. Isso porque as outras agendas, como as notícias de política, cultura, cotidiano ou esporte, por exemplo, também são portadoras de valores afetivos, os quais podem ser definidores de critérios de seleção e tratamento, ainda que não sejam enquadradas como sensacionalistas.

Um afeto como valor-notícia pode estar presente quando a vitória de um famoso esportista ou a condenação judicial de um

3 A lista aqui não encerra todos os afetos explorados por Espinosa, tendo sido priorizados 16 afetos, que são aqueles que evidentemente se contrapõem em termos de definição. Spinoza, em sua obra, ainda aborda outros, como "vergonha", "benevolência", "glória", "humildade", "ira", etc., o que perfaz um total de 47 sentimentos listados (ESPINOSA, 2009, pp. 140-152). 
político corrupto são noticiadas: não se trata somente de critérios objetivos concernentes à relevância pública de seus atores, pois há ali também sentimentos como adoração, esperança e admiração, no caso do esportista, ou, no caso do político, desprezo, ódio e escárnio.

E num momento de comunicação intensificada pelas trocas em redes, que formatam novas interfaces para o jornalismo, tal como se pode observar em redes como o Facebook ou Instagram, ou em portais como o Buzz Feed ou o Huffington Post - que se ocupam por refletir a dinâmica de pulverização da informação na web, quebrando os roteiros tradicionais e específicos de disponibilização de nichos jornalísticos e criando uma ambiência em que notícias advindas de diversos gêneros e temas passam a conviver com proximidade -, fica cada vez mais complexo recorrer a critérios para se estabelecer o que é relevante ou não, pois, segundo Silva (2014, p.67), "os valores-notícia evoluem com o tempo, não constituindo arquétipos imutáveis".

Porém, há de se notar que os afetos transcendem os outros parâmetros de noticiabilidade: sim, seria plausível considerar que critérios como imprevisibilidade, novidade, influência ou raridade (exemplos que podem ser extraídos da tabela da figura 1) sofram forte influência do caminhar da história e dessa comunicação intensificada, estando sujeitos a uma mutabilidade sempre circunstanciada por novos fatores, mas seria este também o caso dos afetos? Seriam os afetos formas de valores-notícia arquetípicos? 


\section{Fotojornalismo e a Dimensão Afetiva da Informação}

Os afetos pertencem a um campo de experiências que foge de uma racionalidade, linearidade ou previsibilidade. É tendo em vista este componente irracional que se deve depositar nas imagens uma reponsabilidade maior nessa modulação de reconhecimento dos afetos como valores-notícia.

Toda imagem porta uma certa arbitrariedade, o que lhe garante a ausência de uma linearidade de leitura. Enquanto no texto o olhar se organiza para linearmente encadear os símbolos e extrair a sua significação, a imagem se impõe exigindo um comportamento multidirecional e mais anárquico do olhar. Em outras palavras, a experiência de confronto com as imagens se dá de forma compatível com esta realidade concreta de um pensamento baseado na "confusão de ideias", confusão esta que respalda Espinosa para definir os afetos.

No caso específico do fotojornalismo, por mais que se busque a objetividade nos fatos representados, os afetos ganham inevitável expressividade. Uma foto pode ser escolhida a partir de um atributo objetivo do fato, mas sabe-se também que esta decisão sempre estará inebriada pela dimensão afetiva que emana da superfície da imagem, o que faz do fotojornalismo o exercício constante dos afetos como valores-notícia. Mas estariam os atores ali envolvidos - fotojornalistas, jornalistas, editores - conscientes de que esta sobreposição dos afetos sobre a objetividade da informação é inevitável no trato das imagens? 
De certa forma, esta sobreposição até pode estar conscientizada, mas deve-se notar que isso tende a ocorrer de forma constrangedora, uma vez que priorizar afetos, em detrimento da informação objetiva, pode ser encarado como uso de puro "sensacionalismo". Ignora-se, nessa maneira de interpretar, que a dimensão afetiva é tão ou mais importante que a dimensão informativa da imagem; que a forma nada consegue expressar se não estiver ancorada numa estratégia afetiva, e que, por fim, este entrelaçamento entre afeto e informação é inevitável no fotojornalismo.

Assim, a resistência oriunda de uma crítica sistemática ao sensacionalismo tende a ser inócua numa realidade de intensa circulação de imagens. É preciso que se note a inevitável preponderância das sensações, isto é, os afetos como valoresnotícia, até porque, na verdade, eles já constituem, desde sempre, uma realidade concreta dentro da prática fotojornalística. Exemplos seriam inúmeros, quase que coincidentes com o mesmo número de fotografias jornalísticas que já tiveram algum destaque no circuito, destaque este que se deu a partir da consolidação deste entrelace entre as dimensões informativas e afetivas.

Necessário, porém, a busca pela percepção de quais afetos estariam imbricados nestas imagens, com vistas ao exercício de decomposição das sensações envolvidas, tendo em vista justamente o caráter mobilizador destas, tal como proposto por Espinosa.

É fato que é bastante comum ao jornalismo uma agenda negativamente afetiva, até pela razão de sua natureza mais essencial, que se pauta preponderantemente pela problematização e denúncia das mazelas sociais, sejam elas em qualquer campo ou de qualquer forma.

Tomando, como exemplo, a reconhecida premiação do 
World Press Photo, nota-se que as imagens premiadas de cada ano, desde a sua criação na década de 1950, abordam guerras, conflitos, tragédias e várias outras vertentes temáticas que se voltam para problemas que afligem um grande contingente humano, reforçando o papel do jornalismo para evidenciar importantes questões de cada época. Uma contextualização que demonstra uma presença constante do medo, desespero, decepção, tristeza, como valoresnotícia, afetos estes, que são considerados, por Espinosa, como refreadores do pensamento e da ação.

Já observando a circulação nas redes sociais, é possível afirmar, por exemplo, que a participação de empresas jornalísticas no Instagram aponta para o reconhecimento e predileção por notícias ou informações que fogem da agenda jornalística voltada para temas mais complexos ou violentos.

Tome-se o caso dos maiores jornais brasileiros ${ }^{4}$, que parece exemplar: o que circula de informação parece ser pautado preponderantemente pelo clima positivamente afetivo das redes, que passa a ser uma espécie de diretriz para se determinar as prioridades sobre o que veicular: entardeceres, amanheceres, paisagens de tirar o fôlego, animais que despertam grande empatia do público ou pequenas histórias de superação são exemplos bastante frequentes de imagens que tem grande aceitação e audiência.

O que tal configuração nas redes sinaliza? Se compreendido em ambas as direções, essa mutualidade entre empresas e público apontaria para uma espécie de consenso para se estabelecer as redes

4 Exame das contas do Instagram dos jornais Folha de S. Paulo, O Estado de S Paulo, O Globo e Zero Hora, cujo resultado foi consolidado no artigo "Considerações sobre a presença do fotojornalismo no Instagram" (SOUZA E SILVA, 2015). 
como um campo mais propenso às informações positivas, isto é, um campo para o exercício dos afetos balizados pela alegria, nos termos de Espinosa? Seria tal comportamento uma resposta ao jornalismo tradicional, o "jornalismo das desgraças", que, ao priorizar violência, conflitos (não somente guerras em si, mas aqueles originados das incertezas e inseguranças da vida em geral) e afins, talvez tenha se construído muito mais se baseando em afetos negativos?

Tem-se assim, um embate entre um jornalismo refreador - por ser baseado em afetos tristes, como o medo e o desespero-e um jornalismo propulsionador, por ser baseado em afetos alegres, como amor, esperança e admiração; embate este que, na verdade, revela a necessidade de se questionar o efetivo papel do jornalismo como narrativa do cotidiano: o que esta agenda positivamente afetiva das redes mobiliza? Por outro lado, em relação às pautas voltadas para os conflitos e mazelas, as quais têm inegavelmente uma relevância social, seria possível tratá-las a partir de valores-notícia positivos, isto é, optar por critérios que valorizem afetos capazes de mobilizar o pensamento e a ação para a resolução destes problemas?

$\mathrm{Na}$ atual circulação de informação da era digital, que parece minar as fronteiras entre o que é e o que não é relevante como notícia, recorrer aos afetos como critério parece ser uma prática cada vez mais frequente, e tal constatação exige trazer à tona mecanismos teóricos para auxiliar as reflexões sobre os impactos dessa forma de selecionar e colocar a informação em circulação.

Estão em jogo os fundamentos éticos para o exercício da prática jornalista. Reconhecer que os afetos, de certa forma, sempre foram utilizados como valores-notícia, sobretudo no fotojornalismo, é um movimento atualmente inevitável, dado o potencial das redes 
como ambientes que garantem uma dinâmica responsiva mais ágil, em que os veículos jornalísticos, praticamente em tempo real, podem observar a reação da audiência, o que permite explorar o papel afetivo e efetivo que a fotografia cumpre no jornalismo conectado e, consequentemente, na vida cotidiana.

Num momento em que a imprensa vem sendo acusada de informar mal, priorizando opinião sobre a informação ou veiculando conteúdos de pouca ou quase nenhuma relevância social, torna-se fundamental tomar consciência dos afetos envolvidos neste processo, que tendem a ser evidenciados se encarados como valores-notícia.

\section{Referências}

ATHANASIOU, Athena; HANTZAROULA, Pothiti; YANNAKOPOULOS, Kostas. Introduction: Towards a new epistemology: the "Affective Turn". In: Performing Emotions: Historical and Anthropological Sites of Affect. Historein, Athens, Greece, v. 8, 2008. Disponível em: https://ejournals.epublishing. ekt.gr/index.php/historein/article/view/2123/1963. Acesso em: 14 jul. 2017.

BORGES, Rosane. A pós-verdade e a miséria do jornalismo. Carta Capital, 8 fev. 2017. Opinião. Disponível em: http://www. cartacapital.com.br/sociedade/a-pos-verdade-e-a-miseria-dojornalismo-contemporaneo. Acesso em: 8 fev. 2017.

CLOUGH, Patricia Ticineto. The affective turn: theorizing the social. Durham: Duke University Press, 2007.

DAMÁSIO, Antônio. Ao encontro de Espinosa: as emoções sociais e a neurologia do sentir. Lisboa: Europa América, 2003. 
DIDI-HUBERMAN, Georges. Que emoção! Que emoção? São Paulo: Editora 34, 2016.

ESPINOSA, Baruch. Ética. São Paulo: Autêntica, 2009.

MATA, Maria José (org.). Imagens e jornalismo. Media \& Jornalismo, Lisboa, ed. 20, v. 11, n.1, 2012.

SILVA, Gislene. Para pensar critérios de noticiabilidade. In: FERNANDES, Mario Luiz; SILVA, G.; SILVA, Marcos Paulo da (org.). Critérios de noticiabilidade: problemas conceituais e aplicações. Florianópolis: Insular, 2014. Cap. 3.

SOUZA E SILVA, Wagner. Considerações sobre a presença do fotojornalismo no Instagram. Tríade: Revista de Comunicação, Cultura e Midia, Sorocaba, v. 3, n. 6, p. 108-123, dez. 2015.

Disponível em: http://periodicos.uniso.br/ojs3/index.php/triade/ article/view/2334. Acesso em: 14 jul. 2017.

SOUZA E SILVA, Wagner. Imagem e subjetividade: narrativas fotográficas confessionais e a estética da afetividade.

Ciberlegenda, Niterói, n. 31, p. 65-75, dez. 2014. Disponível em: http://www.ciberlegenda.uff.br/index.php/revista/article/view/763. Acesso em: 14 jul. 2017.

TARGINO, Maria das Graças. Jornalismo cidadão: informa ou deforma? Brasília: IBICT/ Unesco, 2009. 